\section{The prevalence of transfusion transmitted infections in $A B O$ blood groups and Rh type system}

\author{
Jitendra Singh Nigam, Savitri Singh, \\ Viplesh Kaur, Sumit Giri, Ravi Prakash \\ Kaushal \\ Department of Pathology, Saraswathi \\ Institute of Medical Sciences, Anwarpur, \\ India
}

\begin{abstract}
Screening of blood and blood products is important to reduce the risk of transfusion transmitted infections (TTIs). The transfusion of unscreened or inadequately screened blood and blood products are the major source of TTIs. The aim of this paper is to find out the prevalence of TTIs in ABO blood groups and Rh type system. A total of 4128 blood donors were screened from January 2010 to April 2014. Serological tests were performed for hepatitis B surface antigen (HBsAg), anti hepatitis $\mathrm{C}$ virus (Anti-HCV), anti HIV-1 and 2 , venereal disease research laboratory test (VDRL) and malaria parasite (MP) antigen. In seroreactive donors, HBsAg, Anti-HCV, VDRL, MP antigen and anti HIV were positive in 40 cases, 26 cases, 19 cases, 6 cases and 2 cases, respectively. Highest percentage of HBsAg, Anti HCV, VDRL, MP antigen and anti HIV was observed in blood group A negative $(2 / 50), 0$ negative $(1 / 66)$, B negative (1/91), $\mathrm{AB}$ positive (2/377) blood group respectively. In the present study, the total number of Rhnegative donors is lower when compared to Rh-positive blood donors, but Rh-negative blood donors show higher percentages of seroreactivity for TTIs. Larger scale studies at molecular level are required to improve the knowledge of this aspect.
\end{abstract}

\section{Introduction}

Human blood and blood products are used for the prevention and treatment of various life-threatening diseases however blood transfusion is associated with risk of transfusiontransmissible infections (TTIs) such as Human Immunodeficiency Virus (HIV) infection, Hepatitis B virus (HBV), Hepatitis $\mathrm{C}$ virus (HCV) and syphilis. ${ }^{1}$ The transfusion of unscreened or inadequately screened blood and blood products are the major source of TTI in developing countries like India. ${ }^{2}$ It has been found that genetically determined $\mathrm{ABO}$ blood group antigen which is present in blood may block binding of possible (TTIs) causative organism to polysaccharide on cell but nonsecretor are lacking in their antigen and are at risk to variety of infections (TTIs). ${ }^{3}$ This has been previously found that $\mathrm{ABO}$ blood group antigens are to be associated with the risk of infections and several malignancies. ${ }^{4}$ Present study was carried out to determine the frequency of seroreactivity of TTI agents among the blood donors and to for the determination of any association of blood groups with regards to TTI agents.

\section{Materials and Methods}

This retrospective study was conducted at the blood bank of Saraswathi institute of medical sciences Anwarpur, Hapur, Uttar Pradesh, India, including 4128 donors from January 2010 to April 2014 with male:female ratio of 26:1. Apparently all healthy donors from different localities (rural and suburban population) with age 18 to 65 years, weight not $<45$ kilograms, hemoglobin not $<12.5 \mathrm{~g} / \mathrm{dL}$, normal pulse and blood pressure. Criteria for donor fitness were strictly followed and detailed history was taken to exclude any disease, and should not be professional donor, sexual abusers or drug addictor. All donors were screened and serological report of the individual whether positive or negative for any TTIs was recorded. Written consent approved by ethical committee was taken for all donors. Serological tests were performed for hepatitis B surface antigen (HBsAg), hepatitis $\mathrm{C}$ virus antibodies (AntiHCV), anti-human immunodeficiency virus (anti HIV) -1 and 2, venereal disease research laboratory test (VDRL) and Malaria parasite (MP) antigen by using the National AIDS Control Organization (NACO) approved rapid kits supplied by J. Mitra \& Co. Ltd. (New Delhi, India) and enzyme linked immunosorbent assay (ELISA) technique. All donations were screened by rapid kits followed by ELISA to rule out any false negative or false positive cases. However in present study, no false negative or false positive case was detected.

\section{Results}

A total of 4128 blood donors were screened over the period from January 2010 to April 2014. Male:female ratio was 26:1. Majority of screened donors belonged to 25-35 years age group. Out of the 4128 screened donors, overall $93(2.25 \%)$ were seroreactive cases. In seroreactive donors, $40(0.97 \%)$ cases were reactive for HBsAg, 26 cases (0.63\%) for anti-HCV, 19
Correspondence: Jitendra Singh Nigam, Department of Pathology, Saraswathi Institute of Medical Sciences, Anwarpur, Hapur, Uttar Pradesh 245304, India.

E-mail: nigamjs@gmail.com

Key words: transfusion transmitted infections, blood products, ABO blood groups, Rh type system, India.

Contributions: the authors contributed equally.

Conflict of interests: the authors declare no potential conflict of interests.

Received for publication: 17 August 2014.

Revision received: 16 September 2014.

Accepted for publication: 17 September 2014.

This work is licensed under a Creative Commons Attribution NonCommercial 3.0 License (CC BYNC 3.0).

(C) Copyright J.S. Nigam et al., 2014

Licensee PAGEPress, Italy

Hematology Reports 2014; 6:5602

doi:10.4081/hr.2014.5602

cases $(0.46 \%)$ for syphilis, 6 cases $(0.15 \%)$ for MP antigen and 2 cases (0.05\%) for HIV. Highest percentage of HBsAg was observed in blood group A negative $(4 \%, 2 / 50)$ followed by 0 positive $(1.29 \%, 15 / 1165)$ and A positive $(1.03 \%$, $10 / 973)$. Percentage of anti HCV was more in 0 negative $(1.51 \%, 1 / 66)$ followed by A positive $(0.82 \%, 8 / 973)$. VDRL was commonly observed in $\mathrm{B}$ negative $(1.09 \%, 1 / 91)$ followed by $\mathrm{AB}$ positive $(0.53 \%, 2 / 377)$. Highest percentage of MP antigen was observed in $\mathrm{AB}$ positive $(0.53 \%$, $2 / 377)$ followed by 0 positive $(0.17 \%, 2 / 1165)$. HIV was positive only in 0 negative blood group (Table 1).

\section{Discussion}

To ensure safe supply of blood and blood products the strict and precise screening of donors for transfusion transmissible infections is important. ${ }^{5}$ Das et al. observed that frequency of HBsAg antigen and Anti-HCV among blood donors had maximum association with blood group 0 positive but not statistically significant however Anti-HCV positivity showed highly significant difference between $\mathrm{RhD}$ positive and $\mathrm{RhD}$ negative blood group types. ${ }^{3}$ Behal et al. ${ }^{6}$ observed that RhD negative blood group donors and RhD positive group donors has almost equivalent prevalence rates of $\mathrm{HBsAg}$ but $\mathrm{HBsAg}$ is more prevalent in blood group $\mathrm{B}$ donors and less prevalent in $\mathrm{AB}$ blood group donors. In present study HBsAg is more prevalent in RhD negative blood group A donors and not observed in $\mathrm{RhD}$ negative blood 
Table 1. Transfusion transmitted infections positivity according to blood group types.

\begin{tabular}{|c|c|c|c|c|c|c|}
\hline $\begin{array}{l}\text { Blood } \\
\text { group }\end{array}$ & N. of donors & $\begin{array}{c}\text { HBsAg } \\
\text { positive (\%) }\end{array}$ & $\begin{array}{c}\text { Anti-HCV } \\
\text { positive (\%) }\end{array}$ & $\begin{array}{c}\text { VDRL } \\
\text { positive (\%) }\end{array}$ & $\begin{array}{l}\text { MP-antigen } \\
\text { positive }(\%)\end{array}$ & $\begin{array}{c}\text { HIV } \\
\text { positive (\%) }\end{array}$ \\
\hline $\mathrm{O}+$ & 1165 & $15(1.29)$ & $4(0.34)$ & $6(0.52)$ & $2(0.17)$ & - \\
\hline $\mathrm{O}_{-}$ & 66 & - & $1(1.52)$ & - & - & $2(3.03)$ \\
\hline $\mathrm{B}+$ & 1382 & $11(0.80)$ & $11(0.80)$ & $7(0.51)$ & $1(0.07)$ & - \\
\hline B- & 91 & - & - & $1(1.1)$ & - & - \\
\hline $\mathrm{A}+$ & 973 & $10(1.03)$ & $8(0.82)$ & $3(0.31)$ & $1(0.1)$ & - \\
\hline$A-$ & 50 & $2(4)$ & - & - & - & - \\
\hline $\mathrm{AB}+$ & 377 & $2(0.53)$ & $2(0.53)$ & $2(0.53)$ & $2(0.53)$ & - \\
\hline $\mathrm{AB}-$ & 24 & - & - & - & - & - \\
\hline
\end{tabular}

HBsAg, hepatitis B surface antigen; anti-HCV, anti hepatitis C virus antigen; VDRL, venereal disease research laboratory test; MP, malaria parasite.

group $\mathrm{B}, \mathrm{AB}$ and 0 .

Many study observed that blood group 0 positive has higher seroprevalence of $\mathrm{HBsAg}$, anti HCV, HIV, and VDRL. ${ }^{7-10}$ However Tyagi et al. observed that the negative blood groups are more prone to TTIs and blood Group A negative donors are more affected with HIV, HBsAg and VDRL while blood Group B negative was more commonly affected by HCV. ${ }^{11}$ Similarly in present study RhD negative blood donors (6/225) had higher percentage of seroreactivity than RhD positive blood donors (87/3810) however not statistically significant.

Jeremiah et al. observed that $25 \%, 10 \%$ and $4.1 \%$ of the AB RhD-positive, A RhD-positive and $0 \mathrm{RhD}$-positive respectively are HCV-positive. ${ }^{12}$

In present study, $\mathrm{HBsAg}$ was predominantly observed in RhD negative blood group A donors, anti-HCV in RhD negative blood group 0 , MP antigen in RhD positive blood group $A B$, VDRL in RhD negative blood group B and HIV was seroreactive only in $\mathrm{RhD}$ negative blood group 0 . Behal et al. observed that there is no evidence of any association between sero-positivity for syphilis and ABO blood groups. ${ }^{6}$

Sero-reactivity of these TTI shows that routine screening is a must for blood and blood product for safe transfusion.

\section{Conclusions}

In the present study, total number of RhD negative donors is low as compared to $\mathrm{RhD}$ positive blood donors. This may be because of naturally low frequency of Rh negative blood group type in human population but RhD negative blood donors show higher percentage of sero-reactivity for TTIs. Association of TTIs with blood group and RhD types needs comprehensive large scale studies evaluate their any association with blood group type and to categorize Rh negative donors as high risk donors.

\section{References}

1. Li C, Xiao X, Yin H, et al. Prevalence and prevalence trends of transfusion transmissible infections among blood donors at four Chinese regional blood centers between 2000 and 2010. J Transl Med 2012;10:176.

2. Agarwal N. Response rate of blood donors in the Uttarakhand region of India after notification of reactive test results on their blood samples. Blood Transfus 2012;5:1-3.

3. Das S, Kumar MLH. Association of blood group types to hepatitis B and hepatitis C virus infection among blood donors: a five years institutional based study. Int J Basic Appl Med Sci 2012;2:191-5.

4. Greenwell P. Blood group antigens: molecules seeking a function? Glycoconjugate 1997;14:159-73.

5. Bhawani Y, Rao PR, Sudhakar V. Seroprevalence of transfusion transmissible infections among blood donors in a tertiary care hospital of Andhra Pradesh. Biol Med 2010;2:45-8.

6. Behal R, Jain R, Behal $\mathrm{KK}$, et al.
Seroprevalence and risk factors for hepatitis-B virus infection among general population in northern india. Arq Gastroentrol 2008;45:137-40.

7. Banu A, Ahmed SM, Shastri S. Distribution of Abo and Rh blood groups in HIV seropositives at an integrated counseling and testing centre in Karnataka, India. SAARCTB 2011;8:42-5.

8. Omar AAA, Al-Hayan NN, Mohammed MJ. The infection with HBV and HCV and their relationship to $\mathrm{ABO}$ blood group among blood donors. J Fac Med Baghdad 2012; 54:52-5.

9. Kumar MR, Rao MS, Pulicherla KK, et al. Studies on the distribution of hepatitis $B$ (HBV) and human immunodeficiency virus (HIV): their relation to blood groups and rhesus (Rh) factor in Guntur district of Andhra Pradesh, India. Asian J Pharm Clin Res 2013;6:109-11.

10. Joshi SK, Ghimire GR. Serological prevalence of antibodies to human immunodeficiency virus (HIV) and hepatitis B virus (HBV) among healthy Nepalese males--a retrospective study. Kathmandu Univ Med J 2003;1:251-5.

11. Tyagi S, Tyagi A. Possible correlation of transfusion transmitted diseases with $\mathrm{Rh}$ type and ABO blood group system. JCDR 2013;7:1930-1.

12. Jeremiah ZA, Koate B, Buseri F, Emelike F. Prevalence of antibodies to hepatitis C virus in apparently healthy Port Harcourt blood donors and association with blood groups and other risk indicators. Blood Transfus 2008;6:150-5. 